\title{
El diálogo intercultural hacia la armonía en la diversidad
}

\author{
Demenchonok, Edward (ed.). Intercultural dialogue: In search of \\ harmony in diversity. Newcastle upon Tyne: Cambridge Scholars \\ Publishing, 2014. 402 pp.
}

JOVINO PIZZI

Universidad Federal de Pelotas, Brasil

El libro colectivo Intercultural dialogue: In search of harmony in diversity, editado por Edward Demenchonok, profesor de la Universidad Estatal de Fort Valley, Georgia, Estados Unidos, trata sobre la cuestión del diálogo intercultural y de las relaciones interculturales en el mundo actual. Esta obra reúne a destacados filósofos de seis países (Alemania, China, Estados Unidos, Grecia, India y México) y en ella se plantea un panorama amplio y profundo de la diversidad cultural y las relaciones interculturales. Se trata de una propuesta filosófica que asume una amplísima perspectiva histórica ya que revisa diferentes tradiciones filosóficas, como el daoísmo, el confucionismo, la filosofía de la Grecia Antigua, la de India y las perspectivas contemporánea latinoamericanas y rusas, entre otras.

En este sentido, hablar del tema significa tener en vista la creciente complejidad y los conflictos que vive la Humanidad, pero no como se analiza a veces desde una «guerra entre culturas» o del «choque de las civilizaciones», sino desde la perspectiva de un diálogo intercultural en construcción mutuamente beneficioso, que respete cada cultura como una condición para su mayor florecimiento. En efecto, hablar de diálogo intercultural en un mundo cada vez más conflictivo supone tener claro sobre qué se debe hablar y sobre lo que no. 
Existen visiones y comprensiones idealistas y otras historicistas, existen las perspectivas verdaderas y equivocadas, y hay posibilidades para visiones alternativas. El libro insiste en que el debate no puede jamás polarizarse o sostenerse desde un solo punto de vista, pues la unilateralidad hegemónica significa simplemente más violencia y más injusticias, como se aprecia en muchos lugares. En este sentido, en el prólogo del libro se pregunta precisamente de cuál armonía se debería hablar. Aclarar esa cuestión es una tarea importante de la filosofía, pues evitaría los abusos ideológicos de un lenguaje político muchas veces hipócrita y que, a su vez, aparece reducido al eufemismo de propósitos manipuladores. El doble discurso orweliano no coadyuva a comprender las nociones tan manipuladas de justicia, paz, derechos humanos y democracia en el ágora pública. El diálogo intercultural genuino solamente es posible en la práctica cuando las ideas de diálogo y armonía son pautadas por las exigencias de la no violencia, la paz y una ética planetaria de la corresponsabilidad solidaria.

Tal como sostiene el editor, Edward Demenchonok, la cuestión de la identidad y de la diversidad cultural ha sido una de las grandes pautas valóricas después de la Segunda Guerra Mundial. La segunda mitad del siglo XX, como se sabe, ha sido marcada por el proceso de descolonización y por los movimientos de liberación. Esas cuestiones han sido muy importantes principalmente para América Latina, Asia y África. Pero no es exclusividad de esos pueblos, sino que ha sido una lucha para cambiar el eje geopolítico del eurocentrismo y un esfuerzo para la aclaración de otras formas de comprender el mundo y abrirse a sus contextualizaciones. Ahora, lo más importante es abrirnos a una reflexión crítica y crear unas formas sanas que conduzcan hacia un diálogo intercultural que se expanda planetariamente.

En efecto, la esperanza de un mundo mucho más humano sigue siendo tema de debate filosófico, ya que, como aparece en la introducción, se constata que «muchas culturas han expresado, de un modo o de otro, las ideas del diálogo y de la armonía» (p. 2). Al mismo tiempo, este libro colectivo demuestra que en realidad las culturas son siempre ambivalentes y representan complejidades bastante dispares, en cuyo seno no hay siempre una plena armonía. Dicho de otro modo, en el interior de las culturas mismas no hay relaciones puramente armoniosas. La complejidad cultural representa, pues, un potencial bastante rico, ya que abre posibilidades hacia el desarrollo interactivo cultural y hacia la liberación humana. Mientras tanto, la identidad cultural es también utilizada como una forma ideológica, es decir, un arma peligrosa para los juegos 
políticos de los nacionalismos, racismos y fundamentalismos religiosos.

En este sentido, la libertad cultural supone una responsabilidad frente a la libertad de los otros, o sea, la defensa de la propia libertad significa el respeto a la libertad del otro, una forma de promover la mutualidad benéfica y, por lo tanto, nos impele a hacernos cargo de los grandes beneficios de las relaciones interculturales dialógicas. Tales relaciones representan un punto clave hacia la armonía en el mundo. La negación de la mutualidad en el diálogo significa el riesgo de mayores guerras entre culturas y el final de la convivencia pacífica entre nacionales. De ahí, entonces, los peligros de un conflicto mundial más amplio y más profundo.

El libro se divide en tres partes. La primera de ellas trata de la identidad cultural y del diálogo intercultural como una alternativa a la globalización homogeneizadora. En esta primera parte, los autores ponen de relieve la importancia de las condiciones para la realización del diálogo intercultural. Es un intento para hacer frente a la globalización homogeneizadora y los problemas que ésta genera, y cuyas soluciones solamente pueden ser aclaradas mediante un diálogo intercultural transparente.

En el libro se destacan también la contribución de los filósofos latinoamericanos. Ellos están preocupados con los principios de la interculturalidad como tal y con las condiciones de su realización. Enrique Dussel argumenta que el diálogo intercultural debe tener como fundamento epistemológico y ontológico un diálogo inter-filosófico global. Lo que se trata es de inaugurar un diálogo mundial entre tradiciones filosóficas. Él plantea el problema de la «colonialidad filosófica» y la necesidad de desarrollar un diálogo entre los filósofos de los países del Sur global, para definir la agenda de los problemas filosóficos más urgentes en África, Asia y América Latina. Como una alternativa a la universalidad posmoderna hegemónica, él prevé un mundo trans-moderno emergente como un pluriverso de culturas diferentes en un proceso del diálogo creativo (p. 36).

Raúl Fornet-Betancourt aporta, por su parte, a la fundamentación filosófica la necesidad del diálogo intercultural en un mundo conflictivo. La filosofía intercultural contribuye a la crítica de los obstáculos para un diálogo, los cuales resultan de la instrumentalización objetivante del mundo por la razón calculadora, la «reducción» del otro, las asimetrías del poder, las pretensiones hegemónicas, la marginalización de las culturas tradicionales y la exclusión social de gran parte de la población mundial. El autor señala los momentos claves para la autotransformación intercultural de la filosofía, lo que incluye 
la reestructuración de la «cultura de la razón» a la luz del diálogo de la diversidad (pp. 50-5I). Jorge J. E. Gracia propone una visión familiar-histórica de las identidades sociales, la cual conduce a un diálogo y facilita la comprensión mutua.

La contribución de la filosofía rusa al diálogo intercultural la presenta Demenchonok en su capítulo sobre el pensamiento dialogal de Mikhail Bakhtin. Él muestra que el dialogismo es una característica constitutiva del lenguaje como tal; por lo tanto, las formas diferentes del diálogo (inclusive un diálogo intercultural) tienen como su fundamento el dialogismo inherente del lenguaje (p. II5).

La segunda parte del libro se centra en la búsqueda de la armonía en la diversidad. La armonía (bé) es un concepto clave en la filosofía china. Xin Ru formula algunos de los principios necesarios para promover un diálogo entre las culturas, tales como la igualdad, el respeto mutuo y la tolerancia hacia las diferencias culturales (p. I 8I). Keping Wang articula la relevancia del concepto de armonía para el proyecto de la construcción de una «sociedad armoniosa» en China (p. 202). Xia Chen y Yan Liu comparan las interpretaciones del concepto de armonía en el confucianismo y el daoismo. Xiujuan Chen enfatiza la necesidad de la «autoconciencia cultural» y del diálogo entre la cultura china y otras culturas del mundo (p. 24I). Por su parte, Leonidas Bargeliotes analiza el concepto de armonía en la tradición filosófica de la Grecia Antigua. Todo esto muestra las raíces profundas de las ideas de armonía y del diálogo en las tradiciones culturales que sirven como una base para repensar las complejas relaciones dialógicas y colaborativas en el mundo contemporáneo.

El enfoque filosófico en el diálogo intercultural ayuda a aclarar cuáles son las exigencias con validez universal, sin que por eso se niegue el significado de la diversidad. En efecto, el foco central es la armonía en la diversidad, con lo cual es posible adentrarse en temas como la justicia, la paz, los derechos humanos, la democracia, la no violencia y el orden cosmopolita.

Estos temas se plantean en la tercera parte del texto que tiene como título «El diálogo de la filosofía intercultural frente a los problemas mundiales». Después de la Guerra Fría, el nuevo contexto mundial se presenta con un doble rostro. Por un lado, la esperanza de un mundo mejor pero, por otro, los riesgos de una escalada más acentuada de violencia y de otras amenazas en un mundo unipolar con la hegemonía de una única superpotencia militar, lo que provoca de un modo u otro una carrera armamentista. No se trata solamente de una cuestión militar y del modo de encarar el terrorismo, sino también de 
asumir la crisis ecológica. Una alternativa a esto sería «un mundo libre de cualquier dominación hegemónica» (p. xi). En este caso, se trata de discutir las esperanzas y las oportunidades para la paz y las relaciones colaborativas entre las naciones para solucionar los problemas globales.

William L. McBride critica la teoría de justicia de John Rawls, la que presenta las sociedades occidentales como «casi justas», lo que es ciertamente una ilusión y contradice a las injusticias reales que viven los sujetos. Por eso la lucha contra la injusticia requiere la reorientación hacia las teorías de injusticia. Enrique Dussel critica un sistema político liberal y elabora el proyecto de la democracia participativa articulada con la democracia representativa. La participación activa de los ciudadanos requiere una conscientización y un diálogo creciente. Edward Demenchonok analiza la fundamentación filosófica de la universalidad de los derechos humanos desde la perspectiva de la ética del discurso. Y. V. Satuanarayana muestra que la filosofía de no violencia de Mohandas Gandhi y su concepto de satyagraha son pertinentes en el mundo contemporáneo. Fred Dallmayr critica la dominación hegemónica y la globalización homogeneizadora. Como una alternativa, él examina las posibilidades para una transición hacia un «cosmópolis», una sociedad global que puede emerger en las condiciones del diálogo intercultural y la paz.

Al hacerse cargo de la edición de este libro, por último, el editor Edward Demenchonok ofrece la oportunidad de dar conocer también a otros estudiosos de distintos países del mundo y sus perspectivas filosóficas, las cuestiones relativas al diálogo y la filosofía intercultural. El mérito del libro consiste en una organización coherente del genuino diálogo inter-filosófico y conceptualizar las principales ideas de un libro plenamente universal y polifónico. Este libro es una buena oportunidad para acercarse al tema dialógico y ampliar el debate tan necesario en estos tiempos. Este libro contribuye a la fundamentación filosófica y a la promoción del diálogo intercultural.

\section{Sobre el autor}

Jovino Pizzi es periodista y doctor en Filosofía por la Universidad Jaume I (España). Profesor en la Universidad Federal de Pelotas (Brasil) y actúa en los programas de posgrado en Filosofía y en Educación. Su correo electrónico es <jovino.piz@gmail.com>. 
